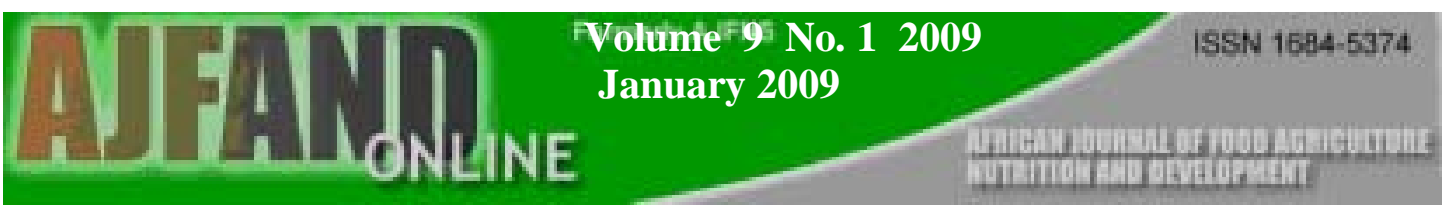

\title{
INDIGENOUS FOOD PROCESSING METHODS THAT IMPROVE ZINC ABSORPTION AND BIOAVAILABILITY OF PLANT DIETS CONSUMED BY THE KENYAN POPULATION
}

\author{
Mary Khakoni Walingo
}

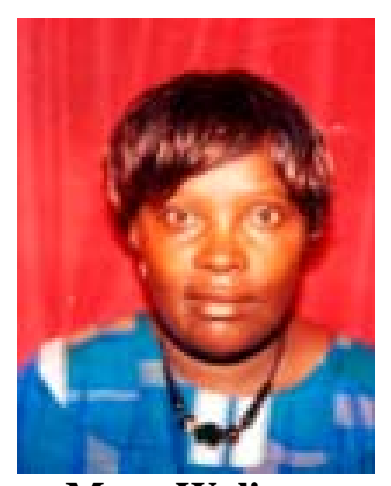

Mary Walingo

Corresponding author: marywalingo@yahoo.com and maelo@maseno.ac.com

Maseno University, School of Public Health and Community Development, P. O. Box 333, Maseno, Kenya.

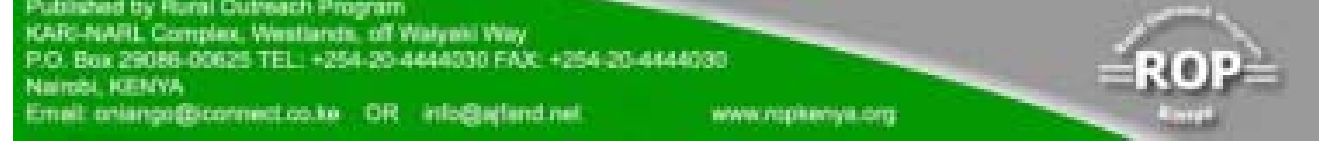




\section{ABSTRACT}

Zinc deficiency is a public health problem associated with pregnancy complications and birth outcomes, impaired immune function, and increased duration and severity of diarrhea in children. Zinc is an essential trace mineral that is a component of over 200 enzymes and is known to be necessary for normal collagen synthesis, mineralization of bones, and is also involved in vital processes such as mitosis, synthesis of DNA and protein, and gene expression and activation. In many low-income countries diets are composed primarily of cereals and legumes which contain phytate that inhibit zinc absorption. Most Kenyan diets are composed of cereals and legumes that have high content of zinc inhibitors, whose levels may be reduced through appropriate food processing technologies at the household level. Indigenous food processing methods like soaking, germination, drying, fermentation, boiling, and roasting, and diet combinations usually reduce the levels of zinc antagonists in the plant diets, thus increasing zinc absorption and bio-availability. These methods are used in combination to both enhance organoleptic properties of food, increasing acceptability and also promoting complementation of nutrients. There are food combination patterns that enhance nutrient bioavailability and complementation that was known to most traditional households and are quickly being forgotten due to changing lifestyles, food preparation methods and food tastes. This is worsened by lack of proper knowledge transfer from the older generation. However, the transfer of indigenous knowledge in food processing, preparation and diet combinations need to be profiled to identify processes that promote nutrient content and bioavailability for improved health and nutrient situation of rural populations whose diets are basically plant based. There is need to identify suitable sources of absorbable zinc and possible suitable dietary combinations that can contribute towards the reduction of zinc deficiency. This paper discusses the indigenous food processing methods that enhance zinc absorption and bioavailability of zinc in local dietary combinations that could reduce zinc deficiency.

Key words: Zinc, soaking, germination, drying, fermentation. 


\section{INTRODUCTION}

Zinc deficiency is a public health problem, and is associated with poor growth [1], decreased immune function [2], increased susceptibility to and severity of infections [3-5], adverse outcomes of pregnancy [6], and neurobehavioral abnormalities [7]. Zinc is an essential trace mineral that is a component of over 200 enzymes and is known to be necessary for normal collagen synthesis and mineralization of bones [89], and is involved in vital processes such as mitosis, synthesis of DNA and protein, and gene expression and activation [10]. In animals, zinc deficiency has been associated with abnormalities in bone growth, bone formation, and mineralization [11]. In humans zinc deficiency has been associated with poor bone health [12] and low bone mass in women [13-14]. Reduced serum or plasma zinc concentrations and urinary zinc have also been reported in women with osteoporosis [15-18].

In many low-income countries diets are composed primarily of cereals and legumes which contain phytate (myo-inositol hexaphosphate), a compound known to inhibit zinc absorption [8]. These diets contain few animal source foods which are rich in zinc and are free of phytates [9]. Approximately one third of children in low-income countries are stunted [19]. Zinc deficiency is presumed to be the underlying cause of stunting and delayed sexual maturation. Zinc supplementation increases linear growth in stunted children [1] which suggests that these high rates of stunting may be due in part to zinc deficiency [19]. Though supplements and fortificants have been used in the control and management of zinc deficiency, dietary combinations of foods that have high levels of phytates, consumed mostly by rural populations may have further complexities regarding bioavailability and utilization of zinc, sometimes creating deficiencies in the body, and negating the purpose of supplementation. This calls for serious consideration of the assessment of the indigenous food preparation methods and diet combinations with implications to zinc nutrition status.

Zinc nutrition status influences the absorption, transport and utilization of vitamin A. The enzyme that plays a major role in the oxidative conversion of retinol to retinal is zinc dependent, and may be adversely affected in zinc deficiency. Total zinc content from the diet and bio-availability from the diet's food combination also influence the efficiency of zinc absorption. Zinc inhibitors like phytates and fibre are present in higher amounts in plant foods, especially cereals and legumes, and influence zinc absorption. Although phytates have been singled out as the most potent dietary inhibitor of zinc bioavailability [20,21], other known inhibitors include oxalate, fibre, EDTA, and polyphenols such as tannins [22].

Most Kenyan diets are composed of cereals and legumes that have high content of zinc inhibitors, whose levels may be reduced through appropriate food processing technologies adopted in households. Maize as a cereal grain is a common staple in most Kenyan diets, and has very high phytate content [23, 24]. When these staples are fermented phytases are produced which break down phytates increasing the amount of available zinc. Zinc deficiency is likely to occur in individuals with low intakes of meat or whose primary zinc sources are poorly bioavailable [25]. Animal sources of food provide higher levels of zinc than plant foods, which are also high in phytic acid

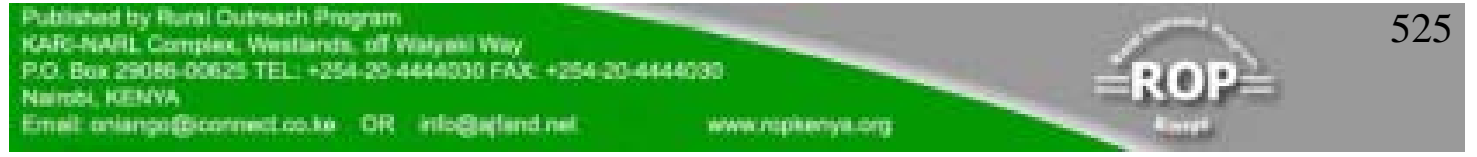


and other constituents that reduce the bioavailability of dietary zinc. Consumption of beef protein increases zinc absorption [26]. Plant foods that are rich in zinc include legumes, nuts, seeds and whole grains are also high in phytic acid, an inhibitor of zinc bioavailability. Unrefined cereal grains, classified as low-zinc bioavailability diets, with a high phytate-zinc ratio, high level of energy in these high-phytate foods and low amounts of proteins [27], compose daily diets of many people.

\section{PREVALENCE OF ZINC DEFICIENCY}

Several micronutrient deficiencies such as those of iron, zinc, vitamin A, folic acid, riboflavin, iodine, calcium and vitamin $\mathrm{E}$ have been reported among pregnant and lactating women, possibly because of low dietary intakes or poor availability of micronutrients [28]. FAO food balance sheets have continued to record a declining trend in the consumption of animal products and fortified food in Africa. Prevalence of zinc deficiency has been estimated at between 36-46\% in pregnant women studied in Malawi [29], lactating women in the Gambia [30], and lactating women in Zaire [31]. Results of these studies have revealed low dietary intakes in bioavailable zinc due to high phytates and fibre, and low intake of animal products.

Zinc and copper deficiencies are prevalent for most age groups in developing countries [32]. Mean intakes of these micronutrients are less than two-thirds of the RDA [33-34]. Global prevalence of inadequate dietary zinc intakes in pregnant women to meet normative needs of pregnancy was estimated at $82 \%$ [35]. Zinc deficiency was reported in $24 \%$ of postpartum women in Indonesia [36], and results in increased rates of infection during pregnancy and lactation [37]. Assessment of dietary intake of zinc in a sample of 100 women revealed a mean intake of $3.7 \mathrm{mg} / \mathrm{d}$ (milligrams per day). Other nutrients included calcium $210 \mathrm{mg} / \mathrm{d}$, phytic acid 1066 $\mathrm{mg} / \mathrm{d}$ and a phytate-zinc ratio of 28 . In this survey $90 \%$ of the subjects were at risk of zinc deficiency. Zinc absorption ranged from $15 \%$ for diets in Malawi, Kenya and Guatemala to 30\% for diets in Ghana, Egypt and Papua New Guinea [38-40].

Assessment of anemia and status of iron, vitamin A and zinc in Kenya found a mean

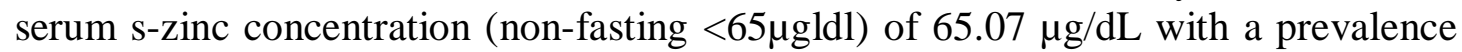
of 50.8\% among children [41]. Zinc deficiency was lowered to $44.2 \%$ when infection was controlled. Sub-regional variations were evident with the Lake Victoria Basin exhibiting higher deficiencies than highlands and semi-arid lowlands. The lake basin is a region where malaria is endemic, a major contributory factor to zinc deficiency. Mean serum zinc concentration in mothers was found to be $63.6 \mu \mathrm{g} / \mathrm{dL}$ with a zinc deficiency prevalence of $52.2 \%$. Controlling for infection reduced prevalence to 47.5 $\%$. Prevalence of zinc deficiency was severe with severity of anemia. Zinc deficiency was more prevalent among pregnant mothers $(68.7 \%)$ than non-pregnant mothers (49.9\%). Mean zinc concentration decreased by $1.79 \mathrm{~g} / \mathrm{dL}$ per month with increase in gestation age [41].

High risk for hypozincaemia is likely to occur in about half of the population in Kenya. The possible risk factors include diarrhea, hookworms and anemia in children. Anemia, respiratory tract illness, hookworm infestation and poor nutrition

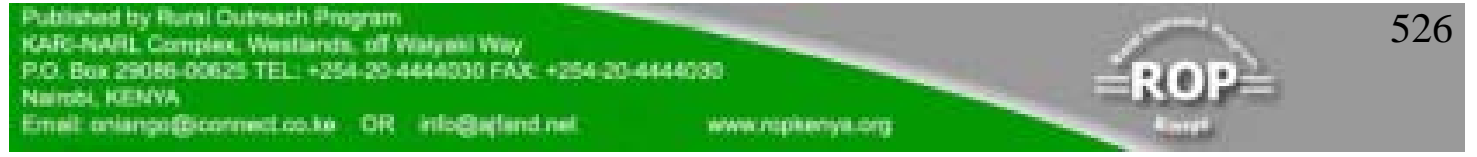


were each associated with two-fold increase in the risk of hypozincaemia. Hypozincaemia is worsened in pregnancy and low plasma zinc concentration would enhance pregnancy complications such as prolonged labor, hypertension, postpartum hemorrhage, spontaneous abortion and congenital malformation. Nutrient requirements increase during pregnancy above the non-pregnant levels to meet the needs of the new physiological status. Nutrient deficiency in pregnancy has serious implications for the fetus and infant, besides increased risk of morbidity and mortality. In Meru region of Kenya, schistosomiasis infection and vitamin A deficiency was associated with two-fold increase in hypozincaemia [41].

\section{ZINC ABSORPTION AND BIOAVAILABILITY}

The balance between absorption facilitators and inhibitors, and the individual's zinc nutrition status determines the bioavailability of zinc from individual foods or from a meal [42-44]. Promoters of zinc absorption include amino acids such as histidine and cysteine [45]. Diets have been classified into high, medium and low-zinc availability based on the absorption of energy from animal sources, the phytate-zinc molar ratio, the amounts of inorganic calcium salts and the methodologies of processing of cereals. Phytate-zinc molar ratio is used to estimate the likely absorption of zinc from a mixed diet. Diets with a phytate-zinc molar ratio greater than 15 have relatively low zinc bioavailability, those with phytate-zinc molar ratio between 5 and 15 have medium zinc bioavailability and those with a phytate-zinc molar ratio less than 5 have relatively good zinc bioavailability [46]. Phytate/zinc molar ratio and calcium/phytate/zinc molar ratios play a major role in inhibiting zinc absorption such that zinc absorption is typically less than $15 \%$ in high phytate meals [47].

Several studies have reported on the fractional and net absorption of zinc under different dietary conditions [48-50]. Although fractional absorption decreases with higher intakes of zinc, the net absorption was greater when total consumption of zinc was increased. This increase was less dramatic in foods that had low phytate levels than in foods with higher phytate levels. Fractional absorption of zinc was further reduced when other minerals were included in the aqueous supplement. Absorption of zinc tripled when white bread was enriched with $3.1 \mathrm{mg}$ zinc chloride to produce a total meal content of $3.5 \mathrm{mg}$ zinc, but not when sufficient zinc was added to the same amount of phytate-containing whole meal bread to produce similar final zinc content. When meals containing chicken meat were enriched with $3.3 \mathrm{mg}$ zinc per meal, fractional absorption fell by only a quarter and net absorption increased by $30 \%$ to $50 \%$. Incubation of dough with yeast for 16 hours before baking reduced phytate-zinc molar ratio of bread containing wheat bran from 17 to 4 and doubled the absorption of zinc. Zinc was absorbed most efficiently from aqueous solutions and from meals containing animal products. Absorption was considerably less from phytatecontaining meals. Fortification of foods with exogenous zinc generally produced a small reduction in fractional absorption, but a positive impact on net absorption. However, fortification of foods with a high phytate-zinc molar ratio had only a small effect on net zinc absorption [51].

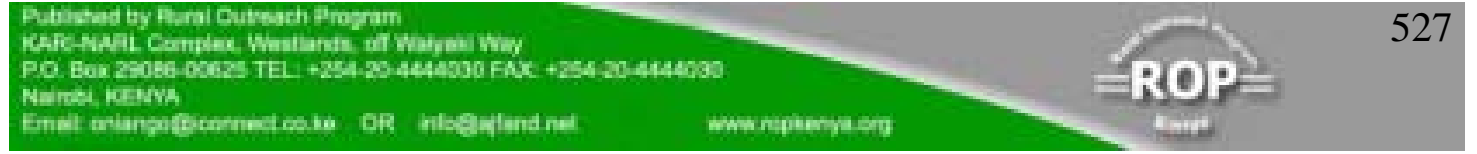


High fibre foods are often associated with diminished zinc absorption. However, refined foods that are low in fibre have substantially lower levels of zinc, so that while relative zinc absorption from low fibre foods is improved, the overall zinc absorption is greater from high fiber foods. For example, almost $40 \%$ of the zinc in white bread (refined) is absorbed, while only $17 \%$ of the zinc in whole grain bread is absorbed [52]. However, the total amount of zinc absorbed from whole grain bread is almost $50 \%$ more than that absorbed from white bread because whole grain bread contains more than three times the level of zinc found in white bread [53].

\section{INDIGENOUS KNOWLEDGE IN THE CONTROL AND PREVENTION OF ZINC DEFICIENCY}

Increased food production, availability of food supply and access are crucial to achieving major nutritional improvements. Wide application of proper technologies and approaches, and development of new concepts that should be transmitted to households and stakeholders are necessary for promotion of dietary interventions in zinc deficiency states. Transfer of indigenous knowledge and skill in food processing, presentation and meal combinations from the older population to the younger, and building on their knowledge for production, processing and preservation of food is necessary for the control of zinc deficiency. There have been notable changes in food selection patterns and traditional methods for preparing and processing of indigenous foods with implications for nutrient retention and bio-availability. The traditional methods are cheaper, acceptable, economically feasible and sustainable means for improved zinc status.

Use of traditional methods requires an understanding of the local dietary patterns, food beliefs, and food consumption patterns of the population to consider the general dietary compositions and combinations, and interactions between the diverse food constituents that antagonize zinc absorption and bioavailability. Such development must consider the cost of foods in terms of accessibility by the general population. One must appreciate challenges in changing dietary habits, attitudes and practices. There are a range of dietary diversification and modification strategies that increase zinc content and bio-availability of plant-derived foods. Dietary approaches are based on promotion of increased consumption of zinc-rich diets and reduction of intake of inhibitors of zinc absorption. Strategies to increase zinc content of the diet are necessary in Kenya where diets are based on cereal staples in zinc.

Dietary diversification includes consumption of zinc rich foods, animal foods and local plants that have high zinc content and indigenous insects. However, zinc and phytate content of local Kenyan plant foods has not been clearly assessed, so as to identify suitable sources of absorbable zinc. There has been a steady decline in the consumption of animal products. Traditionally households kept small livestock such as goats, sheep, rabbits, and pigeons that were consumed at the household level as sources for micro nutrients and proteins. Besides small livestock, mice and wild game were consumed, and fishponds were also developed on small scale house gardens. Farmers selected crop varieties to meet their food needs in the constraints of their environment. They trusted seed from their own landraces to produce a reliable crop.

\begin{tabular}{|c|c|}
\hline 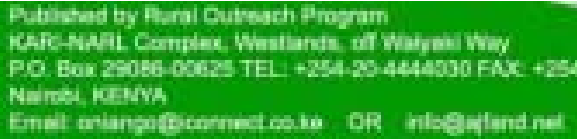 & mww rapteryaceg \\
\hline
\end{tabular}


There were social reasons of custom and prestige, for selection of a diverse range of traditional crops. For example, sorghum was used to brew beers for social functions. Changes in lifestyle and food consumption patterns have affected the production, preparation and preservation of foods. Indigenous knowledge transfer systems are collapsing, creating gaps in knowledge regarding production and utilization of indigenous foods. This is further complicated by the reduced agro-biodiversity in households and communities with devastating effect on food and nutrient diversity of populations.

Indigenous food processing methods and diet combinations usually reduce the levels of anti-nutrients in the plant diets, thus increasing nutrient bio-availability. Such methods include soaking, drying, fermenting, boiling, and roasting. These methods are used in combination to both enhance organoleptic properties of food increasing acceptability and also promote complementation of nutrients. Soaking of cereals and legumes has been used to reduce the phytate content of plant foods. For example, sprouting of beans can dephytinize food products and thus improve zinc bioavailability and also increase the vitamin C content [54]. Drying has been used to preserve meat, fish, cereals, roots and tubers, fruits and green leafy vegetables. Meat and fish are dried over smoke which adds flavor besides increasing shelf life. Such dried fish has readily available zinc [55]. Amino-acid and cystein-containing peptides are released during digestion of cellular animal proteins, enhancing zinc absorption.

Soaking and germination have been used to process foods, reducing levels of antinutrients and increasing nutrient quality of foods. Soaking oats followed by sprouting the oats reduces phytate content and doubles the amount of absorbed zinc in comparison with untreated oats. Zinc content is improved when leavened products are used [56]. Sorghum, for example, is soaked, germinated and is eaten or ground to flour and added to ungerminated cereal flour, reducing the cereal viscosity and activating endogenous cereal phytases that break down phytate into lower inositol phosphates. Soaking and germination enhances enzymatic hydrolysis of phytates. Cereal porridges have been prepared by combining germination and fermentation to improve flavor, digestibility of the products and increase the content of vitamin and minerals. The initial enzymatic changes which precede germination result in both transfer and increase of the B-complex vitamins. It also breaks down the higher carbohydrates and other storage molecules such as calcium, magnesium, and phytate [57].

Fermentation and drying have been used in combination. For example, cassava roots are peeled and grated into pulp, put into cloth bags and set in the sun to drain and ferment. Weights are added onto the bags to press out the moisture for 3-4 days. There is a degree of fermentation and souring. After complete draining, the material is sieved and put in shallow metal pots over a wood fire and is continuously stirred and turned, beating humpy sections to disintegrate them. The other example is maize flour which is soaked, as a thick paste for 3-4 days at ambient temperatures to promote fermentation. The paste is roasted over low heat until golden-brown. It is then sun-dried to reduce the moisture content and to increase the peeping quality. Fermented products are low in soluble fibre and high in insoluble fibre. Organic acids 
produced, such as acetic, lactic, citric, formic and butyric acids, during fermentation potentiate zinc absorption by forming ligands with zinc. Microbial fermentation enhances zinc bio-availability through hydrolysis induced by microbial phytase enzymes. Reduction of phytates in the diet could also favor enhanced absorption of other minerals like calcium and iron. Fermentation reduces the phytate content by releasing endogenous phytases and incorporates yeast during the process [58].

\section{LOSS OF INDIGENOUS KNOWLEDGE}

The adoption of non-Kenyan cultures, changing tastes, diets and lifestyles have negatively influenced the consumption of indigenous foods and contributed to the loss of indigenous knowledge and skills of food preparation, food combinations of nutritional value and food conservation. Time has also become a major constraint in food preparation with populations resorting to convenience and easy to prepare foods that are generally of low nutritional quality, monotonous, and lack variety. Social networks have changed the traditional mode of knowledge transmission. There is failure of knowledge transmission from generation to generation also because of attitude formation relegating these methods into categories of primitive technologies. There is potential for creating awareness of the value of indigenous foods, and preparation and conservation methods. Recipe development offer potential for increased product variety for the changing tastes and for improved marketability of the products.

\section{CONCLUSION}

Diets in Kenya and other low-income countries are composed primarily of cereals and legumes that are high in phytates that inhibit zinc absorption. The high content of zinc inhibitors can be reduced through appropriate traditional food processing technologies adopted in households. The zinc and phytate content of local Kenyan plant foods has not been clearly assessed so as to identify suitable sources of absorbable zinc and possible suitable dietary combinations that can contribute towards the reduction of zinc deficiency. Indigenous food processing methods and diet combinations usually reduce the levels of zinc antagonists in the plant diets, thus increasing zinc bioavailability. Transfer of indigenous knowledge in food processing, preparation and diet combinations for communities need to be profiled to identify processes that promote nutrient content and bioavailability for improved health and nutrient situation of rural populations whose diets are basically plant based with high phytic contents that reduce the bioavailability of zinc. There is need for extensive study of dietary patterns of a population to initiate changes that seek to enhance nutrient content of food and bio-availability. 


\section{REFERENCE}

1. Brown KH, Peerson JM, Rivera J and LH Allen Effect of supplemental zinc on the growth and serum concentrations of prepubertal children: a meta-analysis of randomized controlled trials. Am J Clin Nutr 2002;75:1062-1071.

2. Fraker PJ and LE King Reprogramming of the immune system during zinc deficiency. Annu Rev Nutr 2004;24:277-298.

3. Bhutta ZA, Black RE, Brown KH and Collaborators Prevention of diarrhea and pneumonia by zinc supplementation in children in developing countries: pooled analysis of randomized controlled trials. Zinc Investigators' Collaborative Group. J Pediatr 1999;689-697.

4. Bhuta ZA, Bird SM, Black RE and Collaborators Therapeutic effects of oral zinc in acute and persistent diarrhea in children in developing countries: pooled analysis of randomized controlled trials. Am J Clin Nutr 2000;72:1516-1522.

5. Sazawal S, Black RE and VP Menon Zinc supplementation in infants born small for gestational age reduces mortality: a prospective, randomized, controlled trial. Pediatrics 2001; 108:1280-1286.

6. Caulfield LE, Zavaleta N, Shankar AH and M Merialdi Potential contribution of maternal zinc supplementation during pregnancy to maternal child survival. $A m$ J Clin Nutr 1998; 68 (Suppl) : 499S-508S.

7. Black MM Zinc deficiency and child development. Am J Clin Nutr 1998;68 (Suppl):464S-469S.

8. Calhoun NR, Smith JC and KL Becker The role of zinc in bone metabolism. Clin Orthop 1974;103:212-234.

9. Wallwork JC and HH Sandstead Zinc, In: Simmons DJ, ed. Nutrition and bone development. New York:Oxford University Press, 1990;316-339.

10. McCall KA, Huang $\mathbf{C}$ and CA Fierke Function and mechanism of zinc metalloenzymes. J.Nutr. 2000:130:1446-1473.

11. Yamaguchi M Role of zinc in bone formation and bone resorption. J Trace Elem Exp Med 1998;11:119-135.

12. Alhava FM, Olkkonen H, Puittinen J and VM Nokso-Kovisto Zinc content of human cancellous bone. Acta Orthop Scand 1977;48:1-4. 
13. Freudenheim JL, Johnson NE and EL Smith Relationship between usual nutrient intake and bone mineral content of women 35-65 years of age: longitudinal and cross-sectional analysis. Am J Clin Nutr 1986;44:863-876.

14. Angus RM, Sambrook PN, Pocock NA and JA Eisman Dietary intake and bone mineral density. Bone Miner 1988;4:265-277.

15. Gur A, Colpan $\mathbf{L}$ and $\mathbf{K}$ Nas The role of trace minerals in the pathogenesis of postmenopausal osteoporosis and a new effect of cacitonin. J Bone Miner Metab 2002;20:39-43.

16. Lowe NM, Fraser WD and MJ Jackson Is there a potential therapeutic value of copper and zinc for osteoporosis? Proc Nutr Soc 2002;61:181-185.

17. Hyun, TH, Barrett-Connor $\mathbf{E}$ and DB Milne Zinc intakes and plasma concentrations in men with osteoporosis: the Rancho Bernardo Study. Am J Clin Nutr 2004;80:715-721.

18. Relea P, Revilla M, Ripoll E, Arribas I, Villa LF and HX Rico Zinc, biochemical markers of nutrition, and type I osteoporosis. Age ageing 1995;24:303-307.

19. de Romana DL, Salazar M and KM Hambidge Longitudinal measurements of zinc absorption in Peruvian children consuming wheat fortified with iron only and 1 of 2 amounts of zinc. Am J Clin Nutr 2005;81:637-647.

20. Herzberg M, Foldes J, Steinberg $\mathbf{R}$ and $\mathbf{J}$ Menczel Zinc excretion in osteoporotic women. J Bone Miner Res 1990;5:251-257.

21. Saha PR, Weaver CM and AC Mason Mineral bioavailability in rats from intrinsically labeled whole wheat flour of various phytate levels. J Agric food chem. 1994;42:2531-2535.

22. Larsson M, Hulten LR, Sandstrom B and A Sandberg Improved zinc and iron absorption from breakfast meals containing malted oats with reduced phytate content. $R$ J Nutr 1996;76:677-688.

23. Fordyce EJ, Forbes $\mathbf{R}$ M, Robbins KR and JW Jr Erdman Phytate calcium/zinc molar ratios: are they predictive of zinc bioavailability?. J Food Sci 1987;52:1562-1565.

24. Gibson RS Zinc nutrition in developing countries. Nutr Res Rev 1994;7151-173.

25. Gibson RS Content and bioavailability of trace elements in vegetarian diets. Am J Clin Nutr 1994;59 (Suppl):1223S-1232S. 
26. Sadstead HH Zinc deficiency. A public health problem? Am J Dis Child 1991;145:853-859.

27. Etcheverry P, Keli M, Hawthorne MS, Lily K, Liang MA, Steven A, Abrams MD and IJ Griffin Effect of beef and soy proteins on the absorption of non-heme iron and inorganic zinc in children. J. Am Col Nutr 2006;1:34-40.

28. WHO. Trace elements in human nutrition and health. WHO, Geneva, Switzerland. 1996:343pp.

29. Caulfield LE, Zavaleta N, Shankar AH and M Merialdi Potential contribution of material zinc supplementation during pregnancy to material and child survival. AM. J. Clin. Nutr, 1998; 68: 4495 - 5085.

30. Gibson R and JM Huddle Suboptimal zinc status in pregnant Malawian women: Its association with low intakes of poorly available zinc, frequent reproductive cycling and malaria AM, J Clin, Nutr. 1998: 68:702-709.

31. Yan L, prentice A, Dibba B, Jarajuo LMA, Stirling DM, and S FairweatherTait The effect of long-term calcium supplement of iron, zinc and magnesium status of lactating Gambian women. J. Nutr. 1996;76: 821 - 831.

32. Arnaud JP, Preioai P, Mashako L, Galan P, Nsibu C, Favier A, Kapongo C and Hercberg $\mathbf{S}$ Serum trace elements in Zairean mothers and their new borns. Eur, J.Clin. Nutr. 1994; 48: 341-348.

33. WHO. Trace elements in human nutrition and health. WHO, Geneva, Switzerland. 1996:343pp.

34. Brown KH and SE Weuhler Zinc and human nutrition: Results of recent trials \& implications for program inventions and research. 2000;16.

35. Allen LH Nutrition CRSP: What is marginal malnutrition and does it affect human function? Nutr. Rev., 1993: 51:9; 225-267.

36. Wieringa FT, Dijkhuizen MA, West CE, Mahilal AJ, Hautvast JG and JW Van Der Meer Vitamin A zinc iron deficiency in mothers and infants in Indonesia. International vitamin A consultative Group (IVACG Abstract, Cairo 95). 1997.

37. Caulfield LE, Zavaleta N, Shankar AH and M Merialdi Potential contribution of material zinc supplementation during pregnancy to maternal and child survival. AM. J. Clin. Nutr, 1998; 68: 4495 - 5085.

38. Ferguson EL Gibson RS, Opare - Obisaw C, Oupuu S, Yhompson LU and J Lehrfeld The zinc nutriture of preschool children living in two African countries. J. Nutr, 1998; 45; 609-616. 
39. Carven KR, Gibson RS, Grazioso CF, Isalgue AM, Ruz M and NW Solomons Growth and body composition of periurban Guatemalan children in relation to zinc status: a cross - sectional study. AM J. Clin. Nutr. 1993; 57: 334-343.

40. Murphy SP, Beaton GH and DH Calloway Estimated mineral intakes of toddlers: predicted prevalence of inadequacy in village populations in Egypt, Kenya \& Mexico. Am, J.Clin.Nutr. 1992: 56:565:572.

41. Mwaniki DL, Omwega AM, Munia EM, Mutunga JN, Akelola R, Shako BR, Gotink MH and AM Peter Anemia and status of iron, vitamin A and zinc in Kenya. The 1999 national survey. Overview of findings, conclusions and recommendations. Policy brief in anemia and status of iron, vitamin A and zinc.

42. Cousins RJ Zinc. In: Ziegler E and Filer L. J, Jr, eds. Present Knowledge in Nutrition, $7^{\text {th }}$ edition. Washington, DC: ILSI Press, 1996;293-306.

43. Cheryan M. Phytic acid interactions in food systems. Crit Rev Food Sci Nutr 1980;13:297-335.

44. Kelsay JL, Pranther ES, Clark WM and JJ Canary Mineral balances of man fed a diet containing fiber in fruits and vegetables and oxalic acid in spinach for six weeks. J. Nutr 1988;118:1197-1204.

45. Kies C, Young E and L Mc Endree Zinc bioavailability from vegetarian diets; influence of dietary fiber, ascorbic acid, and past dietary practices. In: Inglet GE Ed. Nutritional bioavailability of zinc. Washington DC: American Chemical Society 1983:115-126.

46. Sandstrom B Bioavailability of zinc. Eur J Clin Nutr 1997;51(S);1:S4-S8.

47. WHO. Revised 1990 estimates of maternal mortality. A new approach by WHO and UNICEF. Geneva, WHO. 1996.

48. Sandstrom B, Arvidsson B, Cederblad A and E Bjorn-Rasmussen Zinc absorption from composite meals. I. The significance of wheat extraction rate, zinc, calcium and protein content in meals based on bread. Am J Clin Nutr 1980;33:739-745.

49. Sandstrom B and A Cederblad Effect of ascorbic acid on absorption of zinc and calcium in man. Intern. J of Vit Nut. Res, 1987:57: 87-90.

50. Flanagan PR,Cluett,J, Chamberian MJ and LS Valberg Dual-Isotope method for determination of human zinc absorption: The use of test meal of turkey meat J.Nutr. 1998:115:112-122. 
51. Sandstrom B, Davidson L, Erickson R. Alpsten M and C Bogentoft Retention of Selenium (75Se), zinc (65Zn) and Manganese (54 Man) in human after intake of labeled vitamin ands mineral supplement. J trace Element and electrophytes in health and diseases, 1987:1: 33- 38.

52. Kannan S Factors in vegetarian diets influencing iron and zinc bioavailability. A continuing education article. www.vegetariannutrition.net/articles/iron-zincBioavailability-in-vegetarian-N.

53. Sandstrom B, Arvidsson B, Cederblad and E Bjorn-Rasmussen Zinc absorption from composite meals. I. The significance of wheat extraction rate, zinc, calcium and protein content in meals based on bread. Am J Clin Nutr 1980;33:739-745.

54. Yadav KN Indigenous legume fermentation: Effect on some antinutrients and invitrodigestability of starch and protein. Food Chem 1994;50:403-406.

55. Gibson $\mathbf{R}$ and $\mathbf{C}$ Hotz Dietary diversification/modification strategies to enhance micronutrient content and bioavailability of diets in developing countries. $\mathrm{Br} J$ Nutr 2001;85(Suppl):2:S159-S166.

56. Ikeda S and T Murakamai Zinc chemical form in some traditional soy foods. J. Food Sci 1995; 60:1151-1155.

57. Akpapunam $M$ and A Sefa-Dedeh Some physiological properties and antinutritional factors of raw, cooked and germinated Jack beans (Canavalia ensiformis). Food Chem 1997; 59:121-125.

58. Kavas A and NEL Sedef Nutritive value of germinated mung beans and lentils. J. Consumer studies Home Econ 1991;15:357-366. 